\title{
Infant feeding indicators for use in emergencies: an analysis of current recommendations and practice
}

\author{
Marie McGrath ${ }^{1}$, Andrew Seal ${ }^{2, *}$ and Anna Taylor ${ }^{1}$ \\ 'Save the Children (UK), 17 Grove Lane, London SE5 8RD, UK: ${ }^{2}$ Institute of Child Health, University College London, \\ 30 Guildford Street, London WC1N 1EH, UK
}

Submitted 26 January 2001: Accepted 10 0ctober 2001

\begin{abstract}
Objective: To assess the applicability and use of infant nutrition and health indicators during emergencies.

Design: Indicators recommended by international health and nutrition organisations for assessing infant feeding practice were compiled and analysed to evaluate their consistency and applicability for use in surveys of emergency-affected populations. These indicators included measures of breast-feeding status, use of artificial feeding, anthropometric status and morbidity. Health and nutrition surveys performed on the resident or refugee population of Kosovo during the years 1996-1999 were then reviewed and the use of infant feeding and morbidity indicators were compared.

Results: A number of recommended indicators exist for assessing infant and child feeding practice which have been generated by different international organisations. A comparison of these indicators revealed a number of inconsistencies, both in target population and measurement method. Their use during the Kosovo crisis was likewise inconsistent and prevented conclusions being drawn about the effectiveness of the international response in protecting infant health and nutrition.

Conclusions: Standard indicators need to be agreed and promoted for use during surveys of emergency-affected populations. Failure to do so will lead to a continued inability to monitor the health and nutrition of infants at a population level during international relief operations.
\end{abstract}

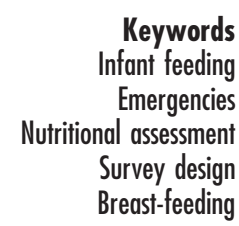

The public health importance of infant feeding in emergencies has been highlighted by recent emergencies in countries such as Iraq and Bosnia, where feeding infants $\dagger$ with breast-milk substitute $\neq$ was common practice. Although there are few epidemiological studies on the impact of emergencies on infant feeding, many anecdotal reports of adverse health outcomes exist. Much of the excess morbidity reported in the 1991 Kurdish Refugee Crisis may have been due to inadequate or inappropriate methods of infant feeding ${ }^{1}$.

The displacement of such populations has created new dilemmas for aid workers on how best to assess and support women feeding infants. In such situations, timely assessment of infant and child feeding practice is essential to quantify and qualify need and appropriately target resources. In addition, careful monitoring and critical

tIn this review the infant is defined as less than 12 months and the young child as $12-36$ months old.

$\ddagger$ Breast-milk substitute is defined as any food being advertised or otherwise represented as a partial or total replacement of breast-milk, whether or not suitable for that purpose (International Code of Marketing of Breastmilk Substitutes, WHO, Geneva, 1981). evaluation are required to determine the impact of humanitarian interventions.

Nutrition and health surveys are frequently used in emergencies to both assess and monitor public health and nutrition. Children aged 6-59 months are traditionally included in anthropometric assessment. Standard anthropometric indicators, e.g. weight-for-height $Z$-scores, and survey methodologies have been developed and are widely used in practice in emergencies. Recommended indicators also exist for assessing infant and child feeding practice and have largely been developed for nonemergency evaluations. However, their applicability and use in emergency assessments and nutritional surveillance have not been critically assessed.

With emerging concerns regarding infant feeding in emergencies, an opportunity arose during the 1999 Kosovo Crisis to research humanitarian interventions in infant feeding in the Former Yugoslav Republic (FYR) of Macedonia. In an attempt to assess the impact of the interventions, a survey on infant and child feeding practice was carried out in two refugee camps in FYR Macedonia. Regional data on infant feeding practice were then collated and compared to allow interpretation of our 
findings. The severe constraints we experienced during this process led us to make a critical review of recommended infant and child feeding practice indicators that exist, their actual use in assessment and surveillance around the 1999 emergency, and their applicability in emergency situations in general.

\section{Methods}

There were two objectives of the review: first, to compile and analyse existing internationally recommended indicators for assessing infant feeding practice and, second, to review the indicators used during a recent emergency for assessing infant feeding practice and morbidity.

\section{Indicators}

Recommended indicators for assessing infant and child feeding practice were identified through contacts and literature searches of international organisations and networks involved in health and nutrition surveillance, and field contact with organisations present in FYR Macedonia during June and July 1999.

\section{Surveys}

The period for which survey data were included spanned three years (1996-1999) and included populations in Kosovo prior to the 1999 crisis, the Kosovar refugees in Macedonia and the returnee population to Kosovo. A total of six surveys were reviewed, based on the inclusion of quantitative or qualitative data and/or significant comment, on infant feeding practice in the Kosovar population (Table 1). For ease of reference, the surveys are numbered in the table and are referred to by number in the text. The surveys were identified primarily through field and headquarter contact with humanitarian organisations operational in FYR Macedonia and Kosovo during the three-year period, and through mail contact and webbased searches of technical organisations and nutrition websites. The abbreviations used for various agencies and organisations are listed in the Appendix.

\section{Results}

\section{Nature and sources offeeding practice indicators}

A number of recommended indicators exist for assessing infant and child feeding practice that have been generated by different international organisations. A comparison of these indicators by definition and source is outlined in Table 2. The indicators included in Table 2 are those that were used in the surveys reviewed and/or which could be considered applicable to emergency situations.

Two types of survey that are widely implemented at regional and national levels in developing and transitional countries are the UNICEF Multi-Indicator Cluster Survey (MICS) and the Demographic and Health Survey (DHS). 
Table 2 Overview and definition of key/recommended indicators for population surveys of infant feeding practice and morbidity

\begin{tabular}{|c|c|c|c|c|}
\hline $\begin{array}{l}\text { Key/recommended } \\
\text { indicators }\end{array}$ & $\begin{array}{l}\text { WHO Indicators for Assessing } \\
\text { Breastfeeding Practices }\end{array}$ & $\begin{array}{l}\text { UNICEF Multiple Indicator } \\
\text { Cluster Survey (MICS) } \\
\text { Indicators for Global } \\
\text { Reporting }\end{array}$ & $\begin{array}{l}\text { Wellstart International Expanded } \\
\text { Programme on Breastfeeding } \\
\text { (EPB) }\end{array}$ & Measure DHS+* \\
\hline Ever breast-fed & $\begin{array}{l}\text { Proportion of infants less than } \\
12 \text { months who were ever } \\
\text { breast-fed }\end{array}$ & & & $\begin{array}{l}\text { Number of infants ( } 0-9 \text { months) and } \\
\text { children ( }<36 \text { months) ever breast-fed }\end{array}$ \\
\hline Never breast-fed & & & $\begin{array}{l}\text { Proportion of infants never given } \\
\text { breast-milk over the proportion of live births, } \\
\text { in a reference time period }\end{array}$ & \\
\hline $\begin{array}{l}\text { Timely initiation of } \\
\text { breast-feeding }\end{array}$ & $\begin{array}{l}\text { Proportion of infants less than } \\
12 \text { months of age who first suckled } \\
\text { within one hour of birth }\end{array}$ & & $\begin{array}{l}\text { Proportion of infants } 0-<12 \text { months } \\
\text { breast-fed within first hour of life }\end{array}$ & $\begin{array}{l}\text { Infants ( } 0-9 \text { months) and children } \\
(<36 \text { months) fed within one hour and } \\
\text { one day of birth }\end{array}$ \\
\hline $\begin{array}{l}\text { Exclusive } \\
\text { breast-feeding rate }\end{array}$ & $\begin{array}{l}\text { Proportion of infants }<4 \text { months } \\
(<120 \text { days) exclusively breast-fed }\end{array}$ & $\begin{array}{l}\text { Proportion of infants }<4 \text { months } \\
\text { ( }<120 \text { days) exclusively breast-fed }\end{array}$ & $\begin{array}{l}\text { Percentage of infants } 0-<6 \text { months } \\
(0-182 \text { days) exclusively breast-fed } \\
\text { based on } 24 \text {-hour recall }\end{array}$ & $\begin{array}{l}\text { Percentage of infants aged }<6 \text { months } \\
\text { ( } 0-182 \text { days) exclusively breast-fed }\end{array}$ \\
\hline $\begin{array}{l}\text { Predominant } \\
\text { breast-feeding rate }\end{array}$ & $\begin{array}{l}\text { Proportion of infants }<4 \text { months } \\
(<120 \text { days) predominantly } \\
\text { breast-fed }\end{array}$ & & $\begin{array}{l}\text { Percentage of infants } 0-<6 \text { months } \\
(0-182 \text { days) predominantly breast-feeding }\end{array}$ & \\
\hline $\begin{array}{l}\text { Continued } \\
\text { breast-feeding rate } \\
\text { at } 12 \text { months }\end{array}$ & $\begin{array}{l}\text { Proportion of children } 12-15 \\
\text { months who are breast-fed }\end{array}$ & $\begin{array}{l}\text { Proportion of children } 12-15 \text { months } \\
\text { who are breast-fed }\end{array}$ & $\begin{array}{l}\text { Percentage of children } 12-<16 \text { months } \\
\text { ( } 366-426 \text { days) who are breast-fed }\end{array}$ & \\
\hline $\begin{array}{l}\text { Continued breast-feeding } \\
\text { rate at } 24 \text { months } \\
\text { Mean duration of } \\
\text { breast-feeding }\end{array}$ & $\begin{array}{l}\text { Proportion of children } 20-23 \\
\text { months who are breast-fed }\end{array}$ & $\begin{array}{l}\text { Proportion of children } 20-23 \text { months } \\
\text { who are breast-fed }\end{array}$ & $\begin{array}{l}\text { Percentage of children } 20-<24 \text { months } \\
(608-730 \text { days) who are breast-feeding } \\
\text { Mean number of months that children are } \\
\text { breast-fed, regardless of other fluids or } \\
\text { liquids received }\end{array}$ & \\
\hline $\begin{array}{l}\text { Median duration } \\
\text { of breast-feeding }\end{array}$ & $\begin{array}{l}\text { The age (months) when } \\
50 \% \text { or more of children are } \\
\text { no longer breast-feeding based on } \\
\text { children under } 36 \text { months }\end{array}$ & & $\begin{array}{l}\text { The age (months) when } 50 \% \text { or more of } \\
\text { children are no longer breast-feeding }\end{array}$ & $\begin{array}{l}\text { Median duration for any, exclusive } \\
\text { and full breast-feeding (any and full } \\
\text { breast-feeding not defined) }\end{array}$ \\
\hline $\begin{array}{l}\text { Frequency of breast-feeding } \\
\text { in } 24 \text { hours }\end{array}$ & & & $\begin{array}{l}\text { Average number of suckling hours reported } \\
\text { within the last } 24 \text { hours in breast-feeding } \\
\text { mothers (one-month age cohort) }\end{array}$ & $\begin{array}{l}\text { Infants }<6 \text { months breast-fed } \\
\text { six or more times in the previous } \\
24 \text { hours }\end{array}$ \\
\hline $\begin{array}{l}\text { Full/partial/token } \\
\text { breast-feeding }\end{array}$ & & & $\begin{array}{l}\text { Proportion of feed types based on } \\
24 \text {-hour recall }\end{array}$ & $\begin{array}{l}\text { Type of food by age and breast-feeding } \\
\text { status based on food frequency table } \\
\text { (recall period not specified) }\end{array}$ \\
\hline Bottle-feeding rate & $\begin{array}{l}\text { Proportion infants }<12 \text { months } \\
\text { ( }<366 \text { days) bottle-fed in previous } \\
24 \text { hours }\end{array}$ & & & \\
\hline $\begin{array}{l}\text { Timely complementary } \\
\text { feeding rate }\end{array}$ & $\begin{array}{l}\text { Proportion of infants } 6-9 \text { months } \\
(180-299 \text { days) receiving } \\
\text { complementary foods in addition to } \\
\text { breast-milk in the last } 24 \text { hours }\end{array}$ & $\begin{array}{l}\text { Proportion of infants } 6-9 \text { months } \\
(180-299 \text { days) receiving } \\
\text { complementary foods in addition to } \\
\text { breast-milk in the last } 24 \text { hours (no. 16) }\end{array}$ & $\begin{array}{l}\text { Proportion of infants } 6-<10 \text { months } \\
\text { (183-304 days) receiving complementary } \\
\text { foods according to breast-feeding status }\end{array}$ & \\
\hline Acute (watery) diarrhoea & $\begin{array}{l}\text { Three or more loose stools in } \\
\text { 24-hour period }\end{array}$ & Three or more loose stools in 24 -hour period & & $\begin{array}{l}\text { Diarrhoea prevalence in the last } \\
\text { two weeks (no case definition) }\end{array}$ \\
\hline $\begin{array}{l}\text { Acute (watery) diarrhoea } \\
\text { in infants }<6 \text { months }\end{array}$ & & $\begin{array}{l}\text { In MICS } 1996 \text { survey of Kosovo, 'gruelly' stool } \\
\text { in breast-fed infant not considered diarrhoea }\end{array}$ & & $\begin{array}{l}\text { Diarrhoea prevalence in the last } \\
\text { two weeks (no case definition) }\end{array}$ \\
\hline $\begin{array}{l}\text { Acute lower respiratory } \\
\text { tract infection }\end{array}$ & $\begin{array}{l}\text { Cough or difficult breathing with } \\
\text { increased breath frequency }\end{array}$ & & & \\
\hline
\end{tabular}

*All DHS indicators listed optionally stratified by demographic characteristics and age. 
Both are potentially key sources of pre-crisis information on health and nutrition.

Demographic and health surveys (DHS) provide information on family planning, maternal and child survival, HIV/AIDS and reproductive health. Key survey indicators on infant and child feeding and morbidity are suggested by Measure DHS+ for obtaining data.* At the time of this review, data from 143 surveys (29 currently underway) were available for 67 countries. In order to improve and standardise evaluation methods in the context of complex emergencies/transitions in subSaharan Africa, a series of manuals that define indicators and methods is planned. At the time of this review there was no information available on what indicators would be included. Currently, DHS does not carry out European regional surveillance and therefore indicators do not strictly apply to this region. However, Measure DHS+ indicators are included in this review of the Kosovo experience since our observations may warrant consideration in devising indicators for use outside Europe.

UNICEF's involvement in MICS in stable situations and in child-related emergency interventions should mean that baseline data to inform emergency assessments and interventions are readily available in many situations. UNICEF has developed a series of indicators for monitoring World Summit for Children goals, which include infant and child nutrition and morbidity ${ }^{2}$. At the mid-decade progress assessment (1996), 60 developing countries had carried out MICS surveys and 40 had incorporated MICS modules in other surveys. The majority of indicators can be measured through sample surveys (e.g. multiple indicator cluster surveys (MICS)) and those relating to infant and child feeding and morbidity prevalence are given in Table 2 .

WHO, as the lead UN technical and scientific organisation, is in the position to provide technical guidance during both stable and emergency nutritional surveillance. WHO indicators included in Table 2 are recommended for the assessment of breast-feeding practice at household level and were developed in consultation with UNICEF and DHS ${ }^{3}$. The WHO Global Data Base on Breastfeeding covers 94 countries and 65\% of the world's estimated infant population. This database pools information from national and regional surveys and studies on breast-feeding prevalence and duration. Additional WHO indicators exist for assessing health facility practices that affect breast-feeding, which may be adapted but are not directly applicable to sample surveys ${ }^{4}$. WHO morbidity indicators for infants are based on standards for communicable disease surveillance ${ }^{5}$.

Wellstart International is a private, non-profit organisation concerned with global breast-feeding promotion and

*Survey key indicators suggested by Measure DHS+ STATcompiler (www.macroint.com). involved in international breast-feeding initiatives including the Innocenti Declaration ${ }^{6}$ and the Baby Friendly Hospitals Initiative (BFHI). Wellstart's Expanded Promotion of Breastfeeding (EPB) has included the development of a practical tool kit for monitoring and evaluating breastfeeding practices and programmes in the field ${ }^{7}$. The tool kit includes a range of breast-feeding indicators for use in sample surveys that are included in Table 2.

\section{Comparison of indicators relating to infant and child feeding}

Comparison of indicators recommended by different international agencies highlighted the following inconsistencies that constrain their effective use (see Table 2).

- The recommended age group in which exclusive breastfeeding rate is measured varies between less than four months (WHO, UNICEF/MICS) and less than six months (EPB, DHS). The prevalence of exclusive breast-feeding is of relevance in emergency situations. However, indicator measurement in different age groups may limit direct data comparisons. This age-group variation may reflect differences in the previously recommended duration of exclusive breast-feeding between WHO (46 months) and the more widely accepted recommendation of 'until about six months' by the World Health Assembly (WHA Resolution 47.5), other UN and international organisations (UNICEF, American Association of Pediatrics, La Leche League International and WABA).

- Timely initiation of breast-feeding is not included as an MICS global indicator. The DHS indicator for timely initiation of breast-feeding applies to different age groups (0-9 months and $<36$ months) than those recommended by WHO or EPB ( $<12$ months), which limits data comparability. The long recall period used for collecting data for some definitions of this indicator increases the risk of introducing systematic bias.

- There are few recommended indicators that can be used to comprehensively assess artificial infant feeding practice. Those recommended by WHO tend to focus on assessing artificial infant feeding only as it impacts on breast-feeding and not on assessing the characteristics of an artificially fed population. This includes the degree and nature of use of infant formula in a population (e.g. exclusive, predominant feeding and the duration of breast-feeding amongst infants no longer breast-fed).

- The indicator for timely complementary feeding recommended by both WHO and MICS is for breastfed infants only. In a population where a proportion of the infants is artificially fed, they would be excluded from this assessment. The EPB indicator recommends complementary feeding rate according to breastfeeding status, which should therefore include nonbreast-fed infants. Timely complementary feeding rate is not included as a DHS indicator, instead type of food 
Table 3 Use of standard/recommended indicators for infant feeding practice

\begin{tabular}{|c|c|c|c|c|c|c|}
\hline \multirow{3}{*}{ Survey number } & \multicolumn{6}{|c|}{ Surveys 1996-1999 } \\
\hline & 1 & 2 & 3 & 4 & 5 & 6 \\
\hline & $\begin{array}{c}\text { IPH (S)/IPH } \\
\text { (M)/UNICEF, } \\
\text { FR Yugoslavia, } \\
1996\end{array}$ & $\begin{array}{c}\text { AAH/MCI/ } \\
\text { UNICEF, } \\
\text { Kosovo, } \\
1998\end{array}$ & $\begin{array}{c}\text { UNHCR/AAH/ } \\
\text { ICMH/UNICEF, } \\
\text { Macedonia, } \\
1999\end{array}$ & $\begin{array}{c}\text { SCF (UK)/ } \\
\text { ICH (L), } \\
\text { Macedonia, } \\
1999\end{array}$ & $\begin{array}{c}\text { AAH, } \\
\text { Kosovo, } \\
1999\end{array}$ & $\begin{array}{c}\text { IRC/IPH } \\
\text { (P)/WHO/CDC, } \\
\text { Kosovo, } \\
1999\end{array}$ \\
\hline Timely initiation of BF & + & & & + & & \\
\hline Exclusive BF rate (EBR) & + & & & + & & \\
\hline Predominant BF rate & + & & & + & & \\
\hline Ever breast-fed rate & + & + & & + & + & \\
\hline Never breast-fed rate & + & + & & + & + & \\
\hline Continued BF rate at 12 months & + & + & & + & & \\
\hline Continued BF rate at 24 months & + & + & & + & & \\
\hline Mean duration of $\mathrm{BF}$ & + & + & & & & \\
\hline Median duration of BF & + & & & & & \\
\hline Frequency of BF in 24 hours & + & & & & & \\
\hline \multicolumn{7}{|l|}{ Full/partial/token BF } \\
\hline Timely CF rate & + & + & & + & & \\
\hline Bottle-feeding rate & + & & & + & & \\
\hline
\end{tabular}

BF - breast-feeding; CF - complementary feeding.

by age ( $0-3$ months, 4-6 months and 7-9 months) and breast-feeding status in children under 36 months is recommended. This is not comparable to the WHO, MICS and EPB indicators.

There is currently no specific definition of diarrhoea for infants under six months. The WHO standard definition of acute watery diarrhoea (three or more loose stools in 24 hours $)^{5}$ closely resembles the minimum number of stools normal for an effectively breast-fed infant (three or more stools in 24 hours $)^{7}$. This greatly limits the interpretation of morbidity data in sample surveys of young infants.

\section{Use of recommended indicators in the Kosovo situation}

Prior to the 1999 crisis, a UNICEF MICS was carried out in Kosovo in 1996, providing a source of baseline data on health and nutrition for the affected population. Subsequent surveys both in Kosovo and in Macedonia were carried out with significant involvement by the UN and other technical agencies (WHO, UNICEF), the CDC, nongovernmental organisations (NGOs) (AAH, MCI, SCF (UK)/ICH) and local public health institutions.

An overview of the use of recommended indicators in the assessment of infant/child feeding practice in these surveys is given in Table 3 . The following observations were made.

- Only two of the seven surveys (surveys 1 and 3) reviewed measured exclusive breast-feeding and predominant breast-feeding rates using the recommended 24-hour recall method $^{3}$. Predominant breast-feeding rate was reported in the 1999 Kosovo survey by CDC (survey 6) but was not based on 24-hour recall.

- The inter-agency anthropometric, nutrition, child health and food security survey (survey 4) carried out in seven refugee camps in Macedonia during the humanitarian response included no recommended indicators on infant feeding and one alternative indicator. However, significant comment on infant feeding practice in the camps was made (see below).

- The 1999 Infant Feeding and Weaning Survey of the returned population (survey 5) included only one recommended indicator (ever breast-fed rate).

- Bottle-feeding rate was included in only two of the surveys reviewed (surveys 1 and 3).

In addition, many alternative indicators and methodologies were used to assess infant/child practice and conclusions drawn despite limited comparability with previous data. These included:

- duration of breast-feeding among those no longer breast-fed (surveys 1, 2 and 3);

- proportion of infants receiving breast-milk, formula milk, cow's milk/other not using 24-hour recall (surveys 4 and 6);

- exclusive and predominant infant formula feeding rates (survey 3);

- current breast-feeding practice based on optional choice of breast-fed, formula fed, cow's milk or nothing (survey 6); and

- collection of historical (e.g. infant feeding practice in older siblings) rather than recent retrospective data (e.g. 24-hour recall), contrary to WHO recommendations (survey 5).

\section{Target populations}

Age groups in which infant and child feeding data were gathered and reported also varied widely, for both recommended and alternative indicators. Feeding practice data on infants under the age of six months were not 
Table 4 Target population and results disaggregated for feeding practice, morbidity and anthropometry

\begin{tabular}{|c|c|c|c|c|c|c|}
\hline \multirow{2}{*}{$\begin{array}{l}\text { Survey } \\
\text { number }\end{array}$} & \multicolumn{3}{|c|}{ Child target population } & \multicolumn{3}{|c|}{ Results reported for infants $<6$ months } \\
\hline & Feeding practice & Morbidity & Anthropometry & Diarrhoea & Acute respiratory infection & Feeding practice \\
\hline 1 & 0-59 months & $0-59$ months & $6-59$ months & No & No & Yes \\
\hline 2 & $6-59$ months & $6-59$ months & $6-59$ months & $\mathrm{N} / \mathrm{A}$ & $\mathrm{N} / \mathrm{A}$ & $\mathrm{N} / \mathrm{A}$ \\
\hline 3 & $0-59$ months & $0-59$ months & $6-59$ months & Yes & Yes & Yes \\
\hline 4 & $0-24$ months & $0-24$ months & Not measured & Yes & Yes & Yes \\
\hline 5 & $\begin{array}{l}\text { Breast-feeding practice: } \\
6-59 \text { months } \\
\text { Infant feeding practice: } \\
6-18 \text { months }\end{array}$ & Not measured & Not measured & $\mathrm{N} / \mathrm{A}$ & $\mathrm{N} / \mathrm{A}$ & $\mathrm{N} / \mathrm{A}$ \\
\hline 6 & $0-24$ months & $0-24$ months & Not measured & No & No & Yes \\
\hline
\end{tabular}

necessarily collected but was sometimes inferred from the practice of older infants and young children. From the target population and data collected comparisons made in Table 4 , there are a number of observations.

- Of the three anthropometric surveys included in this review, none included measurement of infants under six months.

- Two of the surveys (2 and 5) did not include infants under six months old in their infant feeding practice assessment. In one survey (survey 5) infants were defined as 6-18 months rather than the standard less than 12 months ${ }^{3}$, and infant feeding practice data based on this redefined 'infant' group.

- Morbidity was collected and reported for a wide variety of child age groups, limiting direct comparisons of morbidity prevalence. Of the five surveys that collected data for infants under six months, only two reported diarrhoea prevalence in this subgroup (surveys 3 and 4).

\section{Data comparisons}

Variable and alternative data collection methods did not prevent data comparison, interpretation and conclusion on infant feeding practice in survey reports. Comments were often based on observations and experiences of the surveyors or programmes rather than on the quantitative data collected, e.g. the discussion on inappropriate infant feeding practice in the survey in Macedonia camps (survey 4). This suggests that issues considered significant in field practice were not being adequately quantified although they may, in some cases, have been reliably identified using qualitative methods. In the 1999 Health Survey of Kosovo Province (survey 6), significant comments were made regarding Kosovar breast-feeding rates, complementary feeding practice and possible associated child morbidity and mortality rates, although only one indicator of infant feeding practice had been measured. Conclusions appeared to be based on field perceptions and experiences rather than on the actual data presented.

\section{Discussion}

Although the benefits of appropriate infant feeding in terms of child survival are well known, the evaluation of aid impact in terms of morbidity and mortality may not be practical or feasible in emergencies. Changes in prevalence are difficult to measure and cannot be easily attributed to specific interventions and practices. Impact indicators, such as morbidity and anthropometry, have particular constraints when applied to young infants. In particular, interpretation of morbidity data is constrained by difficulties in defining diarrhoea in young infants. It has been suggested that the prevalence of 'acute dehydrating diarrhoea' may be a more appropriate indicator to use then 'acute watery diarrhoea', as dehydration maybe more reliably detected. This proposal needs validation at the field level.

Anthropometry is not routinely measured in infants under six months, an exclusion often based on the assumption that infants under six months are effectively breast-fed and therefore adequately nourished. Practical constraints to anthropometric assessment in this age group also exist and have recently been highlighted ${ }^{8}$. Length references are available only for infants measuring $49 \mathrm{~cm}$ or above, whilst the routine use of weighing scales with $100 \mathrm{~g}$ increments in nutrition surveys lacks the sensitivity required for accurately assessing young infants, both at a population and individual level. In addition, the lack of validated anthropometric references for this age group limits interpretation of any data collected. The widely used NCHS reference values ${ }^{9}$ are based on growth curves of artificially fed infants and there has been accumulating evidence that breast-fed infants have different patterns of growth $^{10}$. Recent revisions of the NCHS references ${ }^{11}$ remain most appropriate for the US population upon which the data are based. WHO has initiated an international multi-centre growth reference study with a view to revising current growth references, including those of young infants. This was scheduled for completion in $2002^{12}$.

In an emergency situation, there may be many indirect influences on infant and child feeding practice. Monitoring of the entire aid process is necessary to evaluate impact, assign responsibility and encourage accountability. Considering the limitations of impact indicators, the use of outcome indicators, e.g. breast-feeding rates, and process indicators, e.g. number mothers enrolled in breast-feeding 
counselling support, may facilitate more comprehensive and responsive monitoring and has been suggested as a practical and appropriate means of evaluation in emergency situations ${ }^{13}$.

During the humanitarian intervention in FYR Macedonia, there were growing concerns about the possible negative impacts of the aid intervention on infant feeding practice ${ }^{14}$. Unsolicited donations of infant formula arrived that were subsequently included in untargeted distributions ${ }^{15}$, contrary to current recommendations $^{16-18}$. Distributions of infant formula and complementary infant foods were largely unmonitored. Baby bottles were included in distributions to refugees in camps and host families and were available through some camp mother and child facilities. Although a variety of recommended outcome indicators of infant and child feeding practice exist, our review demonstrates that they were not widely used during the 1999 Kosovo Crisis. In addition, the use of process indicators to describe and monitor food, logistics and maternal and child health activities was variable and poorly co-ordinated ${ }^{15}$. Thus, observations of bad practice could not be evaluated due to the inadequacies of the assessment methodologies used.

\section{Constraints to using recommended indicators for assessing infant feeding practice in emergencies}

Failure to include recommended indicators and the use of alternative indicators of infant feeding practice may reflect a lack of awareness of current recommendations. The field presence of personnel from WHO and UNICEF in FYR Macedonia did not ensure assessments were made using recommended indicators, nor did the presence and involvement of NGOs experienced in nutrition. Although many recommended infant feeding indicators have been developed and are widely used in non-emergency settings (e.g. BFHI), in reality they have not yet been operationalised in the context of emergencies.

The widespread use of alternative indicators may also reflect gaps in the scope of current assessment tools in emerging emergency situations. Current indicators have been developed particularly to assess breast-feeding practice but few recommend how to assess the extent and nature of artificial feeding in a population. A number of alternative indicators used in Kosovo reflected an identified need to assess artificial feeding practice for which recommended indicators do not exist.

\section{Recommended indicators need to reach consistency in the age groups to which they are applied}

Twenty-four hour recall is currently the recommended food frequency period for assessing breast-feeding and complementary feeding practice. This recommendation was based on the widespread use of 24-hour recall in surveys of dietary intake. However, the 24-hour recall method has been recognised as contributing to a systematic overestimation of exclusive breast-feeding ${ }^{3}$ and underreporting of complementary feeding. The effect of this bias is to reduce the external validity of the population estimate and this would be evident when comparing results obtained from surveys using different methods. However, the problems with the 24-hour recall method have to be balanced against deficits in the other available methods. These include recall bias when including older age groups in retrospective measurements and the impracticality of conducting repeat measures on the same individual.

A further problem with the quantification of many of the indicators discussed above is the small sample size obtainable during routine nutritional cluster surveys which, assuming a total sample size of 900 0-59-monthold children, would approximate 100 infants under six months. This sample size would fail to produce reliable prevalence estimates for many indicators. To tackle this issue alternative sampling strategies may be required, such as the use of optimally biased samples or quality assurance sampling.

There are significant limitations to assessing infant and child feeding in emergencies and the impact of aid interventions. However, these only go some way to explaining the low level and quality of monitoring that was carried out around the 1999 Kosovo Crisis ${ }^{15}$.

\section{Recommendations}

Infants under six months should be included in emergency assessments and monitoring. This may involve rapid qualitative techniques for initial needs assessment. Appropriate indicators of nutritional status, mortality and infant feeding practice should be measured quantitatively where the need for more information is identified.

There is a need to broaden the terms of reference for programme evaluation, from being based largely on impact indicators, such as morbidity, to also include process and outcome indicators of infant and child feeding practice. This requires the promotion and use of recommended infant and child feeding practice indicators as evaluation tools by NGOs, UN agencies and donor organisations.

The varying definitions used for the same indicators amongst recommending organisations require harmonisation. A clear description of key infant feeding indicators that should be included in emergency evaluations and nutrition and health surveys is required for inclusion in field manuals. This requires agreement among recommending organisations as to which age groups infant feeding indicators should be applied.

The scope of existing recommended indicators is not sufficient to assess all feeding issues in emergency situations, particularly in relation to artificially fed populations. The derivation and field trialling of recommended indicators for this population group are necessary 
if appropriate and comparable assessments are to be made.

A review of various sampling strategies to enable reliable estimates of the prevalence of indicators of infant nutrition and health during emergencies is required. Strategies identified as potentially appropriate should be field-tested.

Recommended outcome indicators and sampling strategies for assessing infant and child feeding practice should be developed and included in emergency field manuals of health, nutrition, logistics and donor personnel.

Ultimately, the presence of key personnel in the field is essential to implementing international recommendations and guidelines. There is a need for significant improvement in field technical support in emergencies and, where resources permit, the early field positioning of an infant and child feeding co-ordinator.

\section{References}

1 Yip R, Sharp T. Acute malnutrition and high childhood mortality related to diarrhoea. Lessons from the 1991 Kurdish Refugee Crisis. J. Am. Med. Assoc. 1993; 270: 587-90.

2 UNICEF. End-decade Assessment Indicators for Assessing Progress Globally. CF/EXD 1999-03, Annexe 3. New York: UNICEF, 2000.

3 WHO. Indicators for Assessing Breastfeeding Practices. Report of an informal meeting, 11-12 June 1991. WHO/CDD/SER/91.14. Geneva: WHO, 1991.

4 WHO. Indicators for Assessing Health Facility Practices that Affect Breastfeeding. Report of the Joint WHO/UNICEF Informal Interagency Meeting. WHO/CDR/93.1 UNICEF/SM/93.1. Geneva: WHO, 1992.

5 WHO. World Health Organization Recommended Surveillance Standards. WHO/CDS/CSR/ISR/99.2. Geneva: WHO, Department of Communicable Diseases Surveillance and Response, 2000.

$6 \mathrm{WHO}$ UNICEF. Innocenti Declaration on the protection, promotion and support of breastfeeding. Breastfeeding in the 1990's: A Global Initiative. Italy: WHO/UNICEF, 1990.

7 Wellstart International. Toolkit for Monitoring and Evaluating Breastfeeding Practices and Programs. San Diego, CA: Wellstart International, 1996.

8 Prudhon C. Including infants in nutrition surveys: experiences of ACF in Kabul city. Field Exchange 2000; 9: 15-7.
9 Hamill PVV, Drizd TA, Johnson CL, Reed RB, Roche AF. Growth Curves for Children, Birth to 18 years. US Department of Health, Education and Welfare Publications No. PHD 78-1650. Hyattsville, MD: National Center for Health Statistics, 1977.

10 CDC/NCHS. CDC Growth Charts: United States. No. 314. Hyattsville, MD: National Center for Health Statistics, 2000.

11 Whitehead RG, Paul AA. Longterm adequacy of exclusive breastfeeding: how scientific research has led to revised opinions. Proc. Nutr. Soc. 2000; 59: 17-23.

12 WHO Working Group on the Growth Reference Protocol. A Growth Curve for the 21st Century: The WHO Multicentre Growth Reference Study. Geneva: WHO, 1998.

13 Ad Hoc Group. Infant Feeding in Emergencies. Policy, Strategy and Practice. Report of the Ad Hoc Group on Infant Feeding in Emergencies. London: Ad Hoc Group, 1999.

14 Forsyth V. Report on Infant Feeding Consultancy to FYR Macedonia and Albania. Copenhagen: WHO, 1999.

15 ICH. Meeting the Nutritional Needs of Infants during Emergencies: Recent Experiences and Dilemmas. Report of an international workshop. London: ICH, 1999.

16 Humanitarian charter and minimum standards in disaster response, The Sphere Project, Geneva, 1998.

17 WHO. International Code of Marketing of Breastmilk Substitutes. Geneva: WHO, 1981.

18 WHO. WHO Forty-Seventh World Health Assembly, A47/VR/11, Agenda Item 19, WHA 47.5, 1994.

\section{Appendix}

AAH - Action Against Hunger

CDC - Centers for Disease Control and Prevention

ICH - Institute of Child Health

ILCA - International Lactation Consultant Association

IMCH - Institute of Mother and Child Health, Skopje

IPH - Institute of Public Health

IRC - International Rescue Committee

MCI - Mercy Corps International

NCHS - National Center for Health Statistics

SCF (UK) - Save the Children Fund UK

UNHCR - United Nations High Commissioner for Refugees

UNICEF - United Nations Children's Fund

WABA - World Alliance on Breastfeeding Action

WHA - World Health Assembly

WHO - World Health Organization 